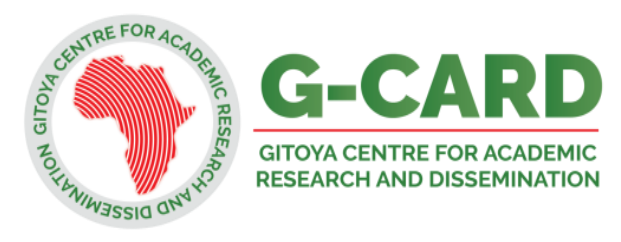

\title{
Relationship between Contextual Factors, Psychosocial Factors and Hygienic Practices of Tribes in Liberia
}

\author{
Kpoeh, Henry Eementary \\ Adventist University of the Philippines \\ *Corresponding author: eekpoeh@yahoo.com
}

\begin{abstract}
This study determined the relationship between contextual factors, psychosocial factors and hygienic practices of the tribes of Liberia. Data were collected from six randomly selected tribes from three regions in Liberia. Convenient, stratified and random sampling techniques were employed to survey 390 household heads who were aged 15 years and above. A correlational design was used and data gathered were analyzed utilizing inferential statistics. Majority of the respondents were males aged 40 years and above and of the middle and high income category. Regression analysis revealed self-efficacy, social environment and cognitive factors as predictors of hygienic practices in terms of disposal of wastes, while self-efficacy, cognitive, policy implementation and cultural identity predicted handwashing. Additionally, social environment, self-efficacy, physical environment, cognitive and policy implementation predicted bathing practices. Respondents who had high income, high educational attainment and of the tribes $C$ and $E$ had a better practice on waste disposal. Those with high income and of the tribes $D$ and $C$ had a better handwashing practice, while those who had high income and of the $A$ and $E$ ethnic groups exhibited better bathing practices.
\end{abstract}

Keywords: Contextual factors, psychological factors, cognitive, culture, self-efficacy, hygienic practices

\section{Introduction}

Hygienic practices are critical to human health and well-being. Two aspects of hygienic practices that demand much attention are sanitation practices and personal hygiene practices. Improper hygienic practices cause infectious diseases which pose huge public health challenges particularly in low and middle-income countries. Notably, a substantial portion of the global infectious disease burden is due to poor hygienic practices (Aunger et al., 2016; Pruss-Ustun et al., 2014). Unless adequately addressed, the world's population will continually face the unchartered burden of hygiene-related diseases.

According to 2012 estimates, inadequate hygienic practices caused 842,000 diarrheal deaths, accounting for $1.5 \%$ of the global disease burden (Pruss-Ustun et al., 2014). An estimated 800,000 children under 5 suffer from diarrhea and India records a quarter with estimated 200,000 deaths (Kotloff et al., 2013). India accounts for about half of the global diarrhea burden among children under 5 (WHO, 2014).

One of the most effective elements of personal hygiene is hand washing. Crucially, only $19 \%$ of the world's population washes hands with soap following usage of a sanitary facility or contact with excreta. The rates of hand washing in middleincome and high-income countries following the above mentioned exposure are $14 \%$ and $43 \%$, respectively (Freeman et al., 2014). However, studies have shown that about $40 \%$ of diarrheal cases are prevented through hand washing with soap (Freeman et al., 2014; Ensink, 2015).

More than 2.5 billion people lack access to improved sanitation facility (WHO and UNICEF, 2013a), while one billion people still practice open 
defecation (WHO and UNICEF, 2013b). In a retrospective analysis of data from 145 low and middle-income countries, about $42 \%$ of households reportedly use unimproved sanitation facility (PrussUstun et al., 2014).

Despite efforts by African governments to improve sanitation to rural settings, sanitary conditions still remain deplorable among informal settlements. In the rural settings of Tanzania, Ethiopia and Sudan, $93 \%, 81 \%$ and $76 \%$ of residents respectively, lack access to improved sanitation. Moreover, around $50 \%$ of urban populations in Kenya, Mali and Liberia lack access to basic sanitation (UNICEF and WHO, 2012).

Global targets to provide adequate water, sanitation and hygiene (WASH) coverage were set under the Millennium Development Goals (MDGs) and the Sustainable Development Goals (SDGs) (Roche, Bain and Cumming, 2017). MDGs, which ended in 2015, met their target for access to safe drinking water in 2010, but not for sanitation. Sub-Saharan Africa (SSA) records one of the lowest rates of WASH coverage worldwide, with $32 \%$ of its population lacking access to improved water at the end of the MDG (JMP, 2015). Also, only $14 \%$ of the people in SSA wash hands with soap following defecation and before eating (Freeman et al., 2014).

Contextual factors such as policy implementation can greatly influence hygiene behavior. In 2002, Ethiopia started its "Health Extension Program (HEP) "emphasizing preventive and curative primary health-care services through promoting sanitation and hygiene. The Ethiopian government, using salaried health workers and voluntary community health promoters was successful in motivating rural households to construct latrine and improve hygiene. The success story of HEP is mostly due to the implementation strategy employed (Newborne and Liisanantti, 2013).

Researchers have documented the impact of psychosocial factors on hygienic practices. In rural Bangladesh, although improved knowledge and awareness of health and environment-related issues enhance hygiene behavior, psychosocial factors such as traditional beliefs and lack of interest in attending cluster meetings influence safe hygiene behavior (Akter and Ali, 2014). Mukadi (2016) found cultural values to influence adoption of WASH practices among 4000 Kenyan households.
Knowledge and self-efficacy have been shown to influence WASH practices. Sonego and Mosler (2014) found self-efficacy to be a predictor of latrine ownership and cleanliness in rural Burundi. Another study found lack of education, under-use of sanitary facilities and rampant roaming of pigs to cause cysticercosis in most parts of Africa (Thys et al., 2016).

Liberia's scenario regarding WASH practices is alarming. In 2013, 35\% of rural inhabitants and 65\% of urban households had access to improved water. Considering sanitation, $12 \%$ of rural households had access to improved sanitation facilities, while only $40 \%$ was for urban households. Rural dwellers reported very low handwashing rates after handling rubbish (16\%), before food preparation (9\%) and following handling baby excreta or diapers (6\%). As for urban dwellers, 19\% wash hands after handling rubbish, before food preparation (11\%) and after handling baby feces or diapers (6\%). Due to inadequate hygienic practices, $39 \%$ of rural households in Liberia have diarrheal cases, with children aged 0-5 years mostly affected, while $23 \%$ of urban settlements have diarrhea (WASH Liberia Baseline Study, 2013).

This study therefore is concerned about access to and practices on sanitation and hygiene among the tribes of Liberia. Further, it aimed at seeking whether contextual and psychosocial factors predict hygienic practices of the tribes of Liberia. The 16year civil unrest that ended in 2005 and the Ebola outbreak in 2014 ravaged Liberia's health sector and economy, apparently tampering with access to and practices on sanitation and hygiene in the country. After these sinister eras, there is a need to do an extensive research on the determinants of hygienic practices of the tribes of Liberia. Hence, this study sought to determine which among the independent variables most significantly predicted hygienic practices and whether there was a significant difference in hygienic practices when income level, educational level, sex, age and tribe are considered.

\section{Research methodology}

This section presents the methodologies employed in gathering and analyzing the data for the study. The section includes the study design, population and sampling techniques, instrumentation, data gathering procedures, ethical considerations and analysis of data. 


\section{Study Design}

This study employed a quantitative, correlational research design to determine the relationship between contextual factors, psychosocial factors and hygienic practices of the tribes. Quantitative design was used since the study orderly acquired quantifiable data, analyzed the data and described the associations among the variables. Relationship was described between the independent variabes and the dependent variable, and the moderating variables and the dependent variable. Correlational design was used to identify predictive relationships among variables, without manipulating the variables. To this end the research figured out which variables were related.

\section{Population and Sampling Techniques}

This study targeted the household heads of six (6) indigenous groups of Liberia. Household head surveyed included a father, a mother, a sibling or any relative who was in charge of the household. The study employed stratified sampling, random sampling and convenient sampling techniques. First, stratified sampling was used to group the tribes into three strata: northern, western and southeastern areas. Second, random sampling was used to select two tribes from each stratum, making the total of six tribes as the study population. The population in each stratum to be sampled was defined by the number of items. A total of 390 household heads, purposively chosen, were surveyed. The distribution of the sample size on the tribes was done using ratio and proportion. The selection of household heads from each of the six tribes was done using simple random sampling where the researcher chose one household after the other. This was done until the required number of respondents from each tribe was obtained. Each tribal community was conveniently chosen based on access to road.

In determining the sample size of the research, the Slovin's formula was utilized:

$$
\begin{aligned}
& \text { 1+N }(e)^{2} \\
& \text { Where } \quad n=\text { sample size } \\
& \quad \begin{array}{l}
N=\text { Population size }(273,212) \\
\text { e }=\text { margin on error }(0.05)
\end{array} \\
& =273212 / 1+273212(0.05)^{2} \\
& =273212 / 684.0 \\
& =399.42 \approx 400
\end{aligned}
$$

The criteria for inclusion were: a) Household head of the six randomly selected indigenous tribes (Bassa, Gola, Grebo, Lorma, Mandingo and Vai), b) age 15 years and above, c) English-speaking, d) ability to give informed consent to participate.

\section{Instrumentation}

The questionnaire was designed based on review of literature and knowledge of the researcher as a doctoral student in Public Health. The questionnaire was also forwarded to experts for validation. After it was validated, the Adventist University of the Philippines (AUP) Center for Graduate Studies (CGS) gave the researcher letter of endorsement to conduct the pilot study. The pilot study was conducted on the Kpelleh tribe, the largest tribe in Liberia. After the reliability test confirmed data validity, the researcher received an endorsement from the Center for Graduate Studies to conduct the actual data gathering. The Kpelleh tribe was excluded from the actual data gathering.

The questionnaire had 125 items and was apportioned into three sections. The first section dealt with the demographic profile of the respondents including, income, educational attainment, sex, age, and tribe. The second section assessed the independent variables (contextual factors and psychosocial factors). The third section assessed the dependent variable- hygienic practices in terms of sanitation practices and personal hygiene practices (handwashing and bathing).

Table 1: Distribution and Retrieval of Questionnaires

\begin{tabular}{llccc}
\hline TRIBE & Population & Questionnaire Distributed & Questionnaire Received & \% of Questionnaire Rec. \\
\hline A & 96,190 & 141 & 137 & 97.2 \\
B & 30,588 & 44 & 44 & 97.8 \\
C & 57,142 & 82 & 82 & 97.6 \\
D & 38,547 & 54 & 54 & 96.4 \\
E & 21,320 & 31 & 31 & 100.0 \\
F & 29,425 & 42 & 42 & 97.7 \\
TOTAL & 273,212 & 390 & 390 & 97.5 \\
\hline
\end{tabular}

Source: Liberia Institute of Statistics and Geo-Information Services (2009) 
Table 1 shows the distribution and retrieval of questionnaires from respondents where $97.5 \%$ of the questionnaires were retrieved. This indicates that the tribes did well in filling in the questionnaires. The $E$ ethnic group recorded the highest percentage of questionnaires retrieved $(100.0 \%)$, followed by the B tribe $(97.8 \%)$, the $F$ tribe $(97.7 \%)$ and the $C$ tribe $(97.6 \%)$. Some respondents, due to busy schedule (farming) and other obligations were unable to fill in the questionnaires and to return them to the researcher.

\section{Pilot Study}

In order to establish reliability and validity of the research instrument, a pilot study was conducted on 75 respondents of the Kpelleh tribe in Sinyea Town, Suakoko District, Liberia. All respondents were chosen based on the set inclusive and exclusive criteria. Cronbach's alpha was utilized to determine the consistency of the instrument. Table 2 indicates the reliability results for each segment of the questionnaire.

Table 2: Reliability Test

\begin{tabular}{lcl}
\hline Questionnaire Section & Cronbach's Alpha & Items \\
\hline Policy Implementation & .631 & 8 \\
Physical Environment & .632 & 11 \\
Social Environment & .642 & 16 \\
Cultural Environment & .748 & 17 \\
Cognitive & .664 & 17 \\
Self-Efficacy & .600 & 10 \\
Accessibility & .744 & 8 \\
Disposal of Waste & .719 & 11 \\
Handwashing & .912 & 18 \\
Bathing & .650 & 9 \\
\hline
\end{tabular}

\section{Data Gathering Procedures}

Upon receiving endorsement from the CGS, the researcher traveled to Liberia to begin the process of data gathering. Upon arrival, the researcher submitted the endorsement and proposal to the Research Department of the Ministry of Health $(\mathrm{MOH})$, Republic of Liberia for approval to conduct the survey questionnaire. After reviewing the proposal, the $\mathrm{MOH}$ gave an approval letter but requested the researcher to submit the proposal to the Ethics Board of Liberia- the Institution Review Board (IRB) for ethical clearance. Afterwards, the researcher moved into the regions where the tribes resided. The researcher liaised with authorities to inform community members through a town crier about the study. Afterwards, the researcher was given permission to meet the respondents.
The researcher recruited and trained three research assistants to assist with the process of data gathering. The researcher explained to the research assistants the essence of the study. They were adequately oriented on the entire data gathering procedures. When instructions were given on how to answer the questionnaire, participants answered the questionnaire without pressure. After responding to the questionnaire, the answered questionnaire items were placed into envelopes. The process of data collection lasted for 10 weeks.

\section{Ethical Considerations}

The study observed ethics as the researcher obtained ethical clearance from the Institution Review Board (IRB) of Liberia for the conduct of the study. Before distributing the questionnaire to respondents, a written consent was secured from each participant. The researcher informed the respondents of anonymity, confidentiality and their limits. They were informed of their exclusive right to decline from the process at any point in time. Because respondents were fully aware of the purpose, benefits and potential risk of the study, and had the right to decline from the study at will, there was no conflict of interest with the respondents or with any third party. The study was void of plagiarism and any other academic fraud, and did not conceal or misrepresent any facts or results discovered during the process of the study. In order to hide identity, participants were not required to write their names on the questionnaire and the tribal groups were assigned letters.

\section{Analysis of the Data}

Data analysis was done through the Statistical Package for Social Science (SPSS). Frequency distribution and percentage were used to describe the demographic profile of respondents. Multiple regression was utilized to determine if any of the independent variables predicted the hygienic practices. One-way ANOVA and T-test were used to examine if hygienic practices of the tribes significantly differed when the moderator variables namely age, sex, educational attainment, income level and tribal affiliation were considered.

\section{Analysis and Results}

This section presents the analyses, results and the interpretation based on the statistical output and related literature. 


\section{Socio-demographics of Respondents}

As shown in table 3 , this section presents the sociodemographics of the respondents in terms of age, sex, income level, educational level and tribal group. Of the total 390 respondents, the age range 39 years and below accounted for 181 (46.4\%), while the age range 40 years and above accounted for majority $(207,53.1 \%)$ of the respondents surveyed. There were two missing data, accounting for $0.5 \%$ because two of the respondents did not indicate their age range.

Table 3: Socio-demographic profile of respondents

\begin{tabular}{|c|c|c|}
\hline Category & $\mathbf{N}$ & Percent \\
\hline \multicolumn{3}{|l|}{ AGE } \\
\hline 39 and Below & 181 & 46.4 \\
\hline 40 and Above & 207 & 53.1 \\
\hline Missing Data & 2 & 0.5 \\
\hline TOTAL & 390 & 100.0 \\
\hline \multicolumn{3}{|l|}{ SEX } \\
\hline Male & 241 & 61.8 \\
\hline Female & 148 & 37.9 \\
\hline Missing Data & 1 & 0.3 \\
\hline TOTAL & 390 & 100.0 \\
\hline \multicolumn{3}{|l|}{ INCOME LEVEL } \\
\hline Below LD 6,000 & 159 & 40.8 \\
\hline LD 6,000 and above & 228 & 58.5 \\
\hline Missing Data & 3 & 0.8 \\
\hline TOTAL & 390 & 100.0 \\
\hline \multicolumn{3}{|l|}{ EDUCATIONAL LEVEL } \\
\hline Elementary & 175 & 49.9 \\
\hline High School & 175 & 49.9 \\
\hline College & 34 & 8.7 \\
\hline Masters & 4 & 1.0 \\
\hline Doctorate & 1 & 0.3 \\
\hline None & 1 & 0.3 \\
\hline TOTAL & 390 & 100.0 \\
\hline \multicolumn{3}{|l|}{ TRIBAL GROUP } \\
\hline Tribe A & 137 & 35.1 \\
\hline Tribe B & 44 & 11.3 \\
\hline Tribe C & 82 & 21.0 \\
\hline Tribe D & 54 & 13.8 \\
\hline Tribe E & 31 & 7.9 \\
\hline Tribe $\mathrm{F}$ & 42 & 10.8 \\
\hline TOTAL & 390 & 100.0 \\
\hline
\end{tabular}

In terms of sex distribution, $61.8 \%$ (241) were males, $37.9 \%$ (148) were females, while there was one missing data constituting $0.3 \%$. When the respondents were classified based on income level, more than half 228 (58.5\%) earned 6,000 Liberian Dollars (LD) and above per month (middle and high income), while 159 (40.8\%) earned less than 6,000 LD per month (low income). In Liberia, about $40 \%$ of female workers are low income earners (earning under 6,000LD per month), compared to $22 \%$ of their male counterparts who are low income earners (LISGIS, 2017). There were three missing data, making up $0.8 \%$ of the respondents.
Respondents' income level was classified into two groups because the other categories of income were not comparable.

Table 3 also shows the educational attainment of respondents where 175 (44.9\%) had elementary education, 175 (44.9\%) had high school diploma, 34 (8.7\%) had bachelor's degree, $4(1.0 \%)$ had masters' degree, $1(0.3 \%)$ had doctorate degree and $1(0.3 \%)$ had non-academic degree. In terms of tribal distribution, Tribe $\mathrm{A}$ and tribe $\mathrm{C}$ had the highest frequency, recording 137 (35.1\%) and 82 (21.0\%), respectively, followed by Tribe $D$ that recorded 54 
(13.8\%) and Tribe B that recorded 44 (11.3\%). Tribe E accounted for the lowest (7.9\%).

\section{Predictors of Hygienic Practices}

This section answers the question regarding which of the independent variables predicted the hygienic practices. Regression analysis was used to determine which independent variables predicted the hygienic practices in terms of disposal of wastes, handwashing and bathing.

\section{Predictors of disposal of wastes}

Table 4 shows the variables that most significantly predicted the disposal of wastes. Three variables came into the regression model. These are selfefficacy, social environment and cognitive (knowledge) which contributed $30.8 \%\left(R^{2}\right.$-Change of .308) to disposal of wastes.

Table 4: Predictors of Disposal of Wastes

\begin{tabular}{lccccc}
\hline \multicolumn{2}{c}{$\begin{array}{c}\text { Unstandardized } \\
\text { Coefficients B }\end{array}$} & $\begin{array}{c}\text { Standardized } \\
\text { Error }\end{array}$ & $\mathbf{T}$ & Sig & $\mathbf{R}^{2}$-Change \\
\hline & .822 & .254 & 3.242 & .001 & .228 \\
(constant) & .456 & .057 & 8.044 & .000 & .041 \\
Self-efficacy & .314 & .060 & 5.228 & .000 & .038 \\
Social environment & .046 & .010 & 4.623 & .000 & \\
Cognitive & .046 & & & & \\
\hline
\end{tabular}

Dependent variable: Disposal of Wastes; $F=57.152, P=.000, R^{2}=0.308$

Self-efficacy is the first variable that entered into the regression model. It has an $F$ value of 57.152, an unstandardized coefficients $B$ of $.456, t$ value of 8.044 and a significant $p=0.000$. Also, self-efficacy contributes $22.8 \%$ (indicated by the $\mathrm{R}^{2}$-Change value of 0.228 ) to disposal of wastes. This shows that selfefficacy has a positive relationship with disposal of wastes. In other words, the higher the self-efficacy, the better the practices on waste disposal. Boisson et al. (2014) confirm this finding. The study assessed latrine construction and use in villagers engaging in open defecation. The findings show modest reduction in open defecation and recommend enhanced village mobilization to increase selfefficacy and tackle the motivations and social norms of open defecation.

In the same vein, Sonego and Mosler (2014) determined factors influencing habitual cleaning behaviour and latrine cleanliness in rural Burundi. The findings reveal self-efficacy, commitment to cleaning and satisfaction with the cleanliness of the latrine as predictors of habitual cleaning of latrines. Winch, Martin and Hulland (2014) conducted a systematic review on factors affecting sustained adoption of water, sanitation and hygiene technologies. Similarly, the study's findings reveal social aspirations and self-efficacy as predictors of adoption of WASH facilities.

The next predictor of disposal of wastes was social environment. It has an unstandardized coefficient $B$ of 0.314 , $t$ value of 5.228 and $p$ value of $\alpha=0.000$. Social environment contributes $4.1 \%$ (indicated by
$R^{2}$-Change value of .041) to disposal of wastes. The regression shows a positive relationship between social environment and disposal of wastes, implying that the better the social environment, the better the disposal of wastes. This finding is in line with a Nigerian study by Aluko et al. (2017) which targeted 300 respondents from 12 randomly selected streets in Ife central local government area. The study found $69.0 \%$ of caregivers to practice safe disposal of feces of children under five. Respondents in this urban settlement had access to improved water sources (93.7\%), improved toilets (64.3\%), with $64 \%$ and $53.7 \%$ having above average knowledge and attitudes, respectively. Another previous study also supports the finding whereby the prevalence of safe disposal of child feces was $81.8 \%$ in Malawian households. Households with higher prevalence of safe child feces disposal were those that had improved sanitation facilities, facilities that are private in urban areas and with older children (UNICEF, 2008).

The third variable that entered the regression was cognitive. It has an unstandardized coefficient $B$ of $.046, t$ value of 4.623 and $p$ value of $\alpha=0.000$. Moreover, the regression model shows that cognitive explains $3.8 \%$ (shown by $\mathrm{R}^{2}$-Change value of .038) of disposal of wastes. This infers that the better the cognitive, the better the disposal of wastes of the respondents. Sara and Graham (2014) agree with the finding when they found good knowledge to be associated with latrine use in Tanzania. A related study found improved knowledge and awareness of health and 
environmental hazards to lead to proper sanitation practices (Akter and Ali, 2014). Another study also found improved knowledge of mothers to be associated with safe disposal of child feces (Azage and Haile, 2015). Furthermore, in Malawi, Chirwa et al. (2017) investigated pit latrine fecal sludge management and found that most people were not willing to pay for emptying services, but households with improved knowledge in one of the study areas showed a higher demand of pit emptying at $84 \%$. In fact, this area had the highest number of lined latrines among the three study areas.

\section{Predictors of handwashing}

Table 5 presents the variables that predict handwashing. It shows that four variables came into the regression model. These are self-efficacy, cognitive, policy implementation and cultural identity. On the overall, the factors contributed $51.7 \%$ ( $R^{2}$-Change of 0.517$)$ to handwashing as shown in Table 5.

Self-efficacy is the first predictor of handwashing as shown in Table 5 . It has an unstandardized coefficient of .935, $t$ value of 13.243 and a significant value of $p=0.000$. Of the four predictors, self-efficacy contributes the highest, $40.8 \%$ (indicated by $R^{2}$-Change value of 0.408 ) to handwashing. This shows a significant positive relationship between self-efficacy and handwashing. The implication is that the higher the self-efficacy, the better the handwashing practice of respondents.

Table 5: Predictors of Handwashing

\begin{tabular}{lccccc}
\hline & $\begin{array}{c}\text { Unstandardized } \\
\text { Coefficients B }\end{array}$ & $\begin{array}{c}\text { Standardized } \\
\text { Error }\end{array}$ & $\mathbf{T}$ & Sig & $\mathbf{R}^{2}$-Change \\
\hline (Constant) & -2.731 & .347 & -7.865 & .000 & \\
Self-efficacy & .935 & .071 & 13.243 & .000 & .408 \\
Cognitive & .077 & .013 & 6.134 & .000 & .059 \\
Policy Implementation & .365 & .064 & 5.682 & .000 & .042 \\
Cultural identity & .227 & .090 & 2.508 & .013 & .008 \\
\hline
\end{tabular}

Dependent variable: Handwashing; $\mathrm{F}=103.022, \mathrm{P}=.000, \mathrm{R}^{2}=0.517$

A study by Curtis et al. (2011) concurs with this result. The study reported that hand hygiene practices greatly depend on in-built psychological factors of the individual such as self-efficacy. Scholz, Nagy, Göhner, Luszczynska \& Kliegel (2009) have also cited socio-cognitive factors such as selfefficacy beliefs, attitude and subjective norms as important predictors of handwashing. Additionally, results from a study among Burundian and Zimbabwean school-going children have found social norms and low self-efficacy to predict poor handwashing practices (Seimetz, Slekiene, Friedrich and Mosler, 2017).

According to Akter and Ali (2014), although improved knowledge and awareness of health and environment-related issues enhance hygiene behavior, psychosocial factors such as traditional beliefs, self-efficacy and lack of interest in attending cluster meetings influence safe hygiene behavior. Similar findings were reported in a study among 4,000 Kenyan households (Mukadi, 2016). Another study found handwashing practice to have a significant association with self-efficacy (Sarani, Balouchi, Masinaeinezhad, and Ebrahimitabs, 2014).

Elsewhere, a Malaysian study found low levels of knowledge, practice and self-efficacy to hinder proper hand washing. The study recorded a significant association between gender $(p=0.004)$, academic achievements ( $p=0.038$ ) and practices ( $p$ $=0.003$ ) with self-efficacy in proper hand washing (Muhamad et al., 2017). As such, Oyibo (2012) has recommended increase in knowledge, practice and self-efficacy as a panacea to ensuring proper hand washing.

Moreover, a study investigated the determinants of hygiene habits of college students in New York. The results reveal that social norms and self-efficacy, rather than scientific knowledge, were predictors of hygiene habits among the students. Freshmen reported such behavior (80.4\%) more than sophomores $(71.9 \%)$, juniors $(67.7 \%)$ or seniors (50\%, $p=.011$ ) (Miko, Cohen, Conway, Gilman, Seward and Larson, 2012).

The next predictor of handwashing was cognitive. Table 5 shows that cognitive has a statistically significant positive relationship with handwashing $(\mathrm{F}=103.022, \mathrm{t}$ value $=6.134, p=0.000)$. It contributes $5.9 \%$ (indicated by the $\mathrm{R}^{2}$-Change value of 0.059) to handwashing. The inference is that the higher the cognitive, the better the handwashing practice of the respondents.

The findings of Akter and Ali (2014) are in agreement with the result of this study. They found hygiene behavior of respondents to be mainly driven by improved knowledge and awareness of 
health and environmental hazards. Another study, Dobe, Mandal and Jha (2013) has indicated the level of education among other factors as significant predictor of handwashing practice. Additionally, a Ghanaian study has reported lack of knowledge on sources of contamination/cross-contamination to be associated with irregular hand washing during food preparation following coughing or sneezing (Kunadu, Ofosu, Abeogye and Tano-Debrah, 2016).

The third predictor that entered the regression model was policy implementation. Table 5 shows that policy implementation has a significant positive relationship with handwashing $(F=103.022$, $t$ value =5.682, $p=0.000, \mathrm{R}^{2}$-change value $\left.=.042\right)$. As indicated by the $\mathrm{R}^{2}$-Change value, policy implementation contributes $4.2 \%$ to handwashing. This implies that the better the policy implementation strategies, the better the handwashing practice of the respondents.

Mukadi (2016) confirms this finding where he found out that community-level planning as part of implementation significantly influenced adoption of WASH practices $(p$-value $0.008<0.005)$ as well as multi-level policy implementation $(p<0.005)$. In Ethiopia, a sustained implementation of its "Health Extension Program (HEP)" motivated rural householders to construct latrine and improve personal hygienic practices such as handwashing (Newborne and Liisanantti, 2013).

Strategies to halt the spread of the Ebola virus included strict policy on hand washing with soap and alcohol, sanitary funeral practices, case isolation and contact-tracing with quarantine (Pandey et al., 2014). Nettey et al. (2016) concur with these findings where they reported strict implementation to improve hand hygiene among others measures, thereby combating the spread of Ebola virus disease.
The fourth variable that predicts handwashing is cultural identity. Table 5 indicates that cultural identity has a statistically significant positive relationship with handwashing ( $F=103.022$, $t$ value $=2.508, p=0.013, \mathrm{R}^{2}$-Change value $\left.=.008\right)$. As per the $\mathrm{R}^{2}$-Change value, cultural identity contributes $0.8 \%$ to handwashing. Even though the contribution of cultural identity is smaller as compared to the previous predictors, it still implies that a better cultural identity can lead to better handwashing.

This finding is in line with the study of Dalibandhu (2016) who found better cultural values of the Yanadi tribe of India to improve personal and community hygiene. Notable among the hygienic practices were handwashing, regular brushing of teeth and washing of clothes twice a week. Another study on Sugali Tribe in India supports this finding where the researchers found cultural identity to account for $37.4 \%$ handwashing with soap following defecation (Venkatashiva, Kusuma, Pandav, Goswami and Krishnan, 2017). Census Organization of India (2011) has reported influence of tribal culture on hygienic practices of Adivasis tribal group as well as the Oraron, Mund and Kisan tribes. However, a Liberian study has found cultural beliefs, among others factors to hamper handwashing with soap (WASH Liberia Baseline Survey, 2013).

\section{Predictors of bathing}

Table 6 shows the variables that significantly predict bathing. Five variables came into the regression model, namely: social environment, self-efficacy, physical environment, cognitive and policy implementation. There is a statistically significant relationship $\left(\mathrm{F}=51.087, p=0.000, \mathrm{R}^{2}\right.$-Change value $=$ $0.399)$ between the five variables and bathing. On the overall, they contribute $39.9 \%$ (indicated by $\mathrm{R}^{2}$ Change of 0.517 ) to bathing.

Table 6: Predictors of Bathing

\begin{tabular}{lccccc}
\hline & $\begin{array}{c}\text { Unstandardized } \\
\text { Coefficients B }\end{array}$ & $\begin{array}{c}\text { Standardized } \\
\text { Error }\end{array}$ & T & Sig & $\mathbf{R}^{2}$-Change \\
\hline (Constant) & .010 & .266 & .038 & .969 & \\
Social Environment & .537 & .064 & 8.419 & .000 & .298 \\
Self-efficacy & .332 & 052 & 6.410 & .000 & .062 \\
Physical Environment & .197 & .058 & 3.380 & .001 & .022 \\
Cognitive & -.026 & .009 & -2.832 & .005 & .011 \\
Policy Implementation & .097 & .047 & 2.067 & .039 & .007 \\
\hline
\end{tabular}

Dependent variable: Bathing; $F=51.087, P=.000, R^{2}=0.399$

The first variable that entered into the regression model is social environment. Table 6 shows that it has a statistically significant positive relationship with bathing (unstandardized coefficient $=0.537, \mathrm{t}$ value $=8.419, p=0.000)$. Social environment contributes $29.8 \%$ (indicated by the $\mathrm{R}^{2}$-Change of 
.298) to bathing. This infers that the better the social environment, the better the bathing practice. However, the researcher did not find any literature on the effect of social environment on bathing.

The next predictor of bathing was self-efficacy. Table 6 shows that self-efficacy has a significant positive relationship with bathing (unstandardized coefficient $=.332, \mathrm{t}$ value $=6.410, p=0.000$ ). As indicated by the $R^{2}$-Change of 0.062 , self-efficacy contributes $6.2 \%$ to bathing. The implication is that the higher the self-efficacy, the better the bathing practice of the respondents.

Physical environment is the third variable that predicts bathing. It has a significant positive relationship with bathing (unstandardized coefficient $=0.197, \mathrm{t}$ value $=3.380, p=0.001$ ) Furthermore, it contributes $2.2 \%$ (indicated by the $\mathrm{R}^{2}$-Change value of .022 ) to bathing practice. This implies that the better the physical environment (source of water), the better the bathing practice of the respondents.

The fourth variable that predicts bathing is cognitive. Table 6 shows that cognitive has a significant negative relationship with bathing (coefficient $\mathrm{B}=-.026$, $\mathrm{t}$ value $=-2.832, p=0.000$ ). As indicated by the $R^{2}$-Change value of 0.011 , cognitive explains $1.1 \%$ of bathing. This shows that the higher the cognitive, the lower or lesser respondents bathe. This further shows a gap between knowledge and practice.

Policy implementation is the last variable that entered the regression model. It has an unstandardized coefficient of .097 , $t$ value of 2.067 and significant $p$ value of 0.039 . As per the $R^{2}$ Change value of 0.007 , policy implementation explains $0.7 \%$ of bathing. The contribution seems small, but it is significant. These values indicate that policy implementation has a statistically significant relationship with bathing. This implies that the better the policy implementation strategies, the better the bathing practice. To the knowledge of the researcher, there is no literature on the relationship between policy implementation and bathing.

\section{Difference in Hygienic Practices by Demographic Profile}

This section determines whether there is a difference in hygienic practices when income level, educational level, sex, age and tribe are considered. Detailed results are presented using T-Test and Oneway ANOVA.

\section{Income}

The t-Test was conducted to identify the difference in hygienic practices by income category. Because the other categories of income level were not comparable, the researcher categorized the respondents' monthly income into two groups: Below 6,000 Liberian dollars (LD) as low income and $6,000 \mathrm{LD}$ and above as middle and high income.

Table 7: Difference in Hygienic Practices by Income

\begin{tabular}{lllllllll}
\hline & Income Category & $\mathrm{N}$ & Mean & SD & t-value & Sig & VI \\
\hline Disposal of Wastes & Below 6,000 LD & 159 & 3.76 & .28 & -4.502 & .000 & Sig \\
& 6000 LD \& Above & 228 & 3.92 & .40 & & & \\
Total & 387 & & & & & \\
Handwashing & Below 6,000 LD & 159 & 2.74 & .36 & -5.919 & .000 & Sig \\
& 6000LD \& Above & 228 & 3.03 & .62 & & & & \\
Bathing & Total & 387 & & & & & \\
& Below 6000 LD & 159 & 3.38 & .31 & -2.443 & .015 & Sig \\
& 6000 LD \& Above & 228 & 3.47 & .38 & & & \\
\hline
\end{tabular}

Table 7 shows that income category has a significant effect on hygienic practices in terms of waste disposal with -4.502 t-value and $0.000 p$-value. Specifically, respondents with high income have higher mean (3.92) and standard deviation (0.40) compared to those with low monthly income who have mean and standard deviation of 3.76 and 0.28 , respectively. This indicates that respondents with high income are more associated with sanitary disposal of wastes compared to those with low income. This further shows that income is key to determining hygienic practices.

This result agrees with a study by Abubakar (2017) who reported significant relationship between type of sanitation facilities and household income $\left(\chi^{2}=\right.$ $23,467.4, p<0.001$ ). About $78.9 \%$ of those using modern sanitation facilities were the richest households. Similar finding was reported in a Ghanaian study which found the use of unimproved 
sanitation facilities and engaging in open defecation to increase with decreasing wealth (Adams, Boateng and Amoyaw, 2016). A previous study confirms this result when it found higher-wealth householders to have more than twice the tendency of using improved sanitation facilities compared to lowerwealth householders (odd ratio: 2.3) (Yohannes, Workicho and Asefa, 2014). En and Gan (2011) found higher socioeconomic status to influence the use of improved sanitation.

According to Azage and Haile (2015), wealthy household is associated with sanitary disposal of child feces. Their finding is consistent with a study that found household with higher wealth quintile to have decreased prevalence odds of cysticercosis due to sanitary disposal of feces (Carabin et al., 2015).

In the same vein, Akter and Ali (2014) found poverty to deprive many households of owning latrine, eventually causing them to engage in open defecation or sharing latrine with neighbors. This finding concurs with a study by Sara and Graham (2014) that found low income to impede household from upgrading sanitation facility in Tanzania. Similar trend was reported in a recent study where socioeconomic status significantly affected WASH practices ( $p<0.01$ ) (Raihan et al. 2017).

Table 7 also indicates that income category has a statistically significant effect on handwashing (tvalue $=-5.919, p=0.000)$. Respondents with high income had a higher mean (3.03) and standard deviation (0.62) than those with low income with 2.74 mean and 0.36 standard deviation. This implies that respondents with high income are associated with better handwashing practice compared to those with low income.

A report from the WASH Liberia Baseline Survey (2013) supports this finding. Accordingly, rural dwellers reported very low handwashing rates after handling rubbish $(16 \%)$, before food preparation $(9 \%)$ and following handling baby excreta or diapers (6\%). As for urban dwellers, $19 \%$ wash hands after handling rubbish, before food preparation (11\%), and after handling baby feces or diapers (6\%). Rabbi and Dey (2013) agree with this finding where they reported higher per capita income as a significant predictor of handwashing. The study of Freeman et al. (2014) also reported that the rates of hand washing in middle-income and high-income countries following the use of a sanitary facility are $14 \%$ and $43 \%$, respectively (Freeman et al., 2014).

Similarly, income category has a significant effect on hygienic practices in terms of bathing ( $\mathrm{t}$-value $=$ 2.443, $p=0.015)$. Particularly, respondents with high income have higher mean (3.47) and standard deviation (0.38) than those with low monthly income with a mean and standard deviation of 3.38 and 0.31 , respectively. This implies that respondents with high income tend to exhibit better bathing practices compared to those with low income.

\section{Educational Attainment}

T-Test was performed to identify the difference in hygienic practices by educational level. Educational attainment was placed into two major categories: elementary and high school levels.

Table 8: Difference in Hygienic Practices by Educational Attainment

\begin{tabular}{|c|c|c|c|c|c|c|c|}
\hline \multicolumn{2}{|c|}{ Educational Attainment } & $\mathrm{N}$ & Mean & SD & t-value & Sig & $\mathrm{VI}$ \\
\hline \multirow[t]{3}{*}{ Disposal of Wastes } & Elementary & 175 & 3.75 & .33 & -2.512 & .012 & Sig \\
\hline & High school & 175 & 3.84 & .32 & & & \\
\hline & Total & 350 & & & & & \\
\hline \multirow[t]{3}{*}{ Handwashing } & Elementary & 175 & 2.76 & .35 & -1.389 & .166 & Not Sig \\
\hline & High school & 175 & 2.81 & .39 & & & \\
\hline & Total & 350 & & & & & \\
\hline \multirow[t]{3}{*}{ Bathing } & Elementary & 175 & 3.40 & .31 & .399 & .690 & Not Sig \\
\hline & High School & 175 & 3.38 & .38 & & & \\
\hline & Total & 350 & & & & & \\
\hline
\end{tabular}

Table 8 shows that respondents' hygienic practice in terms disposal of wastes has a significant difference (t-value -2.512, $p=0.012$ ) between household groups of those who finished elementary and high school levels. This indicates that there is a significant difference in waste disposal between respondents with elementary education and those with high school education. Further, it implies that those with high school education tend to exhibit better waste disposal compared to those with elementary education. A Kenyan study confirms this finding when it found type of sanitation facility and educational level to be related (Koskei, Koskei, Koske and Koech, 2013). Abubakar (2017) further confirms this result when he reported a significant relationship between type of sanitation facility and educational attainment $\left(\chi^{2}=7177.1, p<0.01\right)$. The study by Azage and Haile (2015) found mothers 
having higher education to have ( $A O R=2.16,95 \% \mathrm{Cl}$ : 1.25-3.72) times increased odds of practicing sanitary disposal of child feces when compared to mothers with no education. Sara and Graham (2014) concur with this finding when they found education to be significantly related to latrine use in Tanzania. However, En and Gan (2011) disagree, arguing that maternal literacy does not differ with the use of improved sanitation among children.
T-Test was performed to identify the difference in hygienic practices by sex. Table 8 indicates that the difference in hygienic practice of respondents in terms of disposal of wastes is not statistically significant ( $\mathrm{t}$-value $=0.285, p=0.776)$. This means that there is no significant difference in disposal of wastes between male and female. In other words, males and females basically carry out the same practices on disposal of wastes.

\section{Sex}

Table 9: Difference in Hygienic Practices by Sex

\begin{tabular}{|c|c|c|c|c|c|c|c|}
\hline & Sex & $\mathrm{N}$ & Mean & SD & t-value & Sig & $\mathrm{VI}$ \\
\hline \multirow{3}{*}{ Disposal of Wastes } & Male & 241 & 3.86 & .37 & .285 & .776 & Not Sig \\
\hline & Female & 148 & 3.85 & .37 & & & \\
\hline & Total & 389 & & & & & \\
\hline \multirow[t]{3}{*}{ Handwashing } & Male & 241 & 2.90 & .52 & -.466 & .656 & Not Sig \\
\hline & Female & 148 & 2.93 & .58 & & & \\
\hline & Total & 389 & & & & & \\
\hline \multirow[t]{3}{*}{ Bathing } & Male & 241 & 3.43 & .37 & -.360 & .719 & Not Sig \\
\hline & Female & 148 & 3.44 & .34 & & & \\
\hline & Total & 389 & & & & & \\
\hline
\end{tabular}

Table 10: Difference in Hygienic Practices by Age

\begin{tabular}{llcccccc}
\hline & Age & $\mathrm{N}$ & Mean & SD & t-value & Sig & VI \\
\hline Disposal of Wastes & $39 \&$ below & 181 & 3.83 & .38 & -1.116 & .265 & Not Sig \\
& 40 \& above & 207 & 3.87 & .35 & & & \\
Handwashing & Total & 388 & & & & & \\
& $39 \&$ below & 181 & 2.90 & .49 & -.356 & .722 & Not Sig \\
Bathing & 40 \& above & 207 & 2.92 & .59 & & & \\
& Total & 388 & & & & & \multirow{2}{*}{ Not Sig } \\
& $39 \&$ below & 181 & 3.43 & .36 & .100 & .921 & \\
& 40 \& above & 207 & 3.43 & .35 & & & \\
& Total & 388 & & & & & \\
\hline
\end{tabular}

This result contradicts the finding of Adams, Boateng and Amoyaw (2016) who found gender and the use of type of sanitation facility to be related. Another study agrees with this result when it found older women more likely to use latrines than men (Jenkins, Freeman and Routray, 2014). Also, a study by Thys et al. (2015) found men to be more hesitant than women in neglecting open defecation. Men, by virtue of the patrilineal system, were responsible to build toilets, but mostly preferred open defecation.

Also, Table 9 indicates that hygienic practices in terms of handwashing with t-value $=-0.446, p=$ 0.656 has no significant difference between male and female. This implies that there is no significant difference in handwashing practices between males and females. This finding is supported by Borchgrevink, Cha and Kim (2013) who reported that gender has no relationship with differences in handwashing rates. Similarly, Table 9 shows that hygienic practices in terms of bathing has no significant difference by sex (t-value $=-0.360, p=$
0.719). This means that there is no significant difference in bathing between male and female.

\section{Age}

T-Test was conducted to identify difference in hygienic practices by age. Table 10 shows that respondent' waste disposal is not significant by age (t-value $=-1.116, p=0.265$ ). This means that there is no significant difference in waste disposal between age group 39 years and below and 40 years and above. In other words, age group does not determine hygienic practices in terms of waste disposal.

This finding agrees with a Tanzanian study that found statistically non-significant association between age and latrine adoption (Sara and Graham, 2014). By contrast, a Nigerian study reported significant difference $(p=0.002)$ in age distribution in terms of adherence to hygiene and sanitation practices (Fafunwa et al. 2017). Moreover, mothers or caregivers whose child was 
48-59 months of age (AOR=2.21, 95\% Cl: 1.82-2.68) were more likely to practice sanitary disposal of child feces than mothers or caregivers whose child was less than 12 months old (Azage and Haile, 2015).

Table 10 further indicates that difference in handwashing of respondents does not significantly differ by age category ( $\mathrm{t}$-value $=-0.356, p=0.722$ ). This implies there is no significant difference in handwashing of respondents between age group 39 years and below and 40 years and above. It further shows that age difference does not determine hygiene behavior in terms of handwashing. This finding contradicts the study by Duru et al. (2016) who reported age $(p<0.0001)$ to have a statistically significant association with the level of hygienic practices such as handwashing.
Also, table 10 shows that age does not have a significant effect on hygienic practices in terms of bathing (t-value $=0.100, p=0.921$ ). This means that there is no difference in bathing habits between respondents who fall in the age group 39 years and below and 40 years and above. In other words, age difference does not determine hygiene behavior in terms of bathing.

\section{Tribe}

One-way ANOVA was conducted to identify the difference in hygienic practices by tribe. As shown in Table 11, there is a significant difference in disposal of wastes considering tribal group $(F=13.189, p=$ $0.000)$.

Table 11: Difference in Hygienic Practices by Tribal Group

\begin{tabular}{|c|c|c|c|c|c|c|c|}
\hline & Tribe & $\mathrm{N}$ & Mean & SD & F-value & Sig & VI \\
\hline \multirow[t]{7}{*}{ Disposal of Wastes } & $A$ & 137 & 3.80 & .36 & 13.189 & .000 & Sig \\
\hline & B & 44 & 3.83 & .33 & & & \\
\hline & $\mathrm{C}$ & 82 & 4.07 & .32 & & & \\
\hline & $\mathrm{D}$ & 54 & 3.61 & .43 & & & \\
\hline & $E$ & 31 & 3.93 & .31 & & & \\
\hline & $\mathrm{F}$ & 42 & 3.85 & .27 & & & \\
\hline & Total & \multicolumn{2}{|c|}{ 390further } & 3.85 & .37 & & \\
\hline \multirow[t]{7}{*}{ Handwashing } & $A$ & 137 & 2.91 & .44 & 17.013 & .000 & Sig \\
\hline & B & 44 & 3.03 & .55 & & & \\
\hline & $\mathrm{C}$ & 82 & 3.09 & .53 & & & \\
\hline & $\mathrm{D}$ & 54 & 3.14 & .48 & & & \\
\hline & $E$ & 31 & 2.90 & .50 & & & \\
\hline & $\mathrm{F}$ & 42 & 2.44 & .48 & & & \\
\hline & Total & 390 & 2.91 & .55 & & & \\
\hline \multirow[t]{7}{*}{ Bathing } & $A$ & 137 & 3.69 & .30 & 31.031 & .000 & Sig \\
\hline & B & 44 & 3.31 & .21 & & & \\
\hline & $\mathrm{C}$ & 82 & 3.20 & .38 & & & \\
\hline & $\mathrm{D}$ & 54 & 3.33 & .28 & & & \\
\hline & $E$ & 31 & 3.69 & .32 & & & \\
\hline & $\mathrm{F}$ & 42 & 3.38 & .30 & & & \\
\hline & Total & 390 & 3.44 & .36 & & & \\
\hline
\end{tabular}

In particular, respondents from tribe $C$ had the highest mean of 4.07 (SD $=0.32$ ), followed by Tribe $E$ with a mean of $3.93(S D=0.31)$, and Tribe $F$ with a mean of 3.85 (SD $=0.27)$. Tribe $D$ recorded the lowest mean of $3.61(S D=0.43)$. This means that

Tribe $C$ has the best practice on waste disposal followed by Tribes E and F. Also, it means Tribe D has the least practice on disposal of wastes. This finding is supported by a Nigerian study that reported a statistically significant relationship between household ethnicity and type of sanitation facility (Abubakar, 2017). In India, Venkatashiva, Kusuma, Pandav, Goswami and Krishnan (2017) conducted a community-based cross-sectional study on 500 households of the Sugali Tribe. The researchers found $84.8 \%$ of the tribe to defecate in the open. Further, a study by Jimenez, Cortobius and Kjellen (2014) on water, sanitation and hygiene among indigenous people reported low coverage of sanitation and eventual open defecation. Awunyo- 
Akaba et al. (2016) agree with these results, where tribal land ownership and land rights led to high prevalence of shared latrine and open defecation among indigenous communities in Ghana.

Based on the results in Table 11, respondents' handwashing practice significantly differs among the tribes $(F=17.013, p=0.000)$. Specifically, Tribe $D$ has the highest mean of $3.14(S D=0.48)$, followed by Tribe $C$ with a mean of $3.09(S D=0.53)$ and then Tribe $B$ with a mean of $3.0(S D=0.55)$. Tribe $F$ records the least mean of $2.44(S D=0.48)$ followed by Tribe $\mathrm{E}$ (Mean $=2.90, \mathrm{SD}=0.50)$. This means that Tribe $D$ has the best practice on handwashing, followed by Tribes $C$ and $B$. On the other hand, the least practice on handwashing was carried out by Tribe $\mathrm{F}$ and Tribe $\mathrm{E}$.

Similarly, Table 11 presents a significant difference in respondents' bathing by tribal group $(F=31.031, p$ $=0.000)$. Particularly, Tribe $A$ and Tribe $E$ had the highest means of $3.69(S D=0.30)$ and $3.69(S D=$ 0.32 ), respectively. This was followed by Tribe $F$ with a mean of $3.38(S D=0.30)$ and Tribe $D$ with a mean of $3.33(S D=0.28)$. Tribe $C$ recorded the least mean of 3.20 (SD = 0.38). This implies that Tribes $A$ and $E$ had the best practice on bathing followed by Tribe $\mathrm{F}$. By contrast, Tribe $\mathrm{C}$ records the least practice on bathing. This result corresponds with an Indian study that found the Yanadi tribe to be engaged in good hygienic practices such as bathing (Dalibandhu, 2016).

\section{Conclusions and Recommendations}

The study shows that self-efficacy, social environment and cognitive factors predicted disposal of wastes, while self-efficacy, cognitive, policy implementation and cultural identity were predictors of handwashing. Additionally, social environment, self-efficacy, physical environment, cognitive and policy implementation predicted bathing practices. This indicates that the better the self-efficacy, social environment, cognitive factors, policy implementation and cultural identity, the higher the likelihood of engaging in improved hygienic practices. Therefore, there is need to improve the social and physical environments, selfefficacy, cognitive factors as well as policy implementation strategies in order to realize improved hygienic practices of the indigenous people in Liberia.
Gender and age did not differ significantly in hygienic practices. However, poor hygienic practices were seen among respondents of poorer households. Tribal affiliation differed significantly in hygienic practices, while educational attainment differed significantly only in disposal of wastes. Therefore, there is need to improve the socioeconomic status, to address unhygienic cultural practices and to conduct health promotion programs in order to create behavioral changes leading to improved hygienic practices.

\section{References}

Abubakar, I.R. (2017). Access to Sanitation Facilities among Nigerian Households: Determinants and Sustainability Implications. Sustainability, 9:547.doi: 10.3390/su9040547.

Adams, E.A., Boateng, G.O. \& Amoyaw, J.A. (2016).Socioeconomic and demographic predictors of potable water and sanitation access in Ghana. Soc. Indic. Res. doi:126:673-687.

Aker, T., \& Ali, A.M. (2014). Factors influencing knowledge and practice of hygiene in Water, Sanitation and Hygiene (WASH) programme areas of Bangladesh Rural Advancement Committee. Rural Remote Health. 14(3):2628.

Aluko, O.O., Afolabi, O.T.A. Olaoye, E.A., Adebayo, A.D., Oyetola, S.O. and Abegunde, O.O. (2017). The management of the faeces passed by under five children: an exploratory, cross-sectional research in an urban community in Southwest Nigeria. BMC Public Health.; 17: 178. doi: 10.1186/s12889-017-4078-1.

Aunger, R., Greenland, K.,Ploubidis, G., Schmidt, W., Oxford, J. \& Curtis, V. (2016). The Determinants of Reported Personal ad Household Hygiene Behaviour: A MultiCountry Study. PLOS ONE 11(8): e0159551.https://doi.org/10.1371/journal.p one.0159551.

Awunyo-Akaba, Y., Awunyo-Akaba, Y., Gyapong, M., Senah, K., Konradsen, F. \& Rheinländer, T. (2016). Sanitation 
investments in Ghana: An ethnographic investigation of the role of tenure security, land ownership and livelihoods. BMC Public Health. 16: 594. doi:10.1186/s12889-0163283-7.

Azage, M. \& Haile, D. (2015). Factors associated with safe child feces disposal practices in Ehtiopia evidence from demographic and health survey. Arch Public Health. (70):40. doi: 10.1186/s13690-015-0090-z. eCollection 2015.

Boisson, S., Sosai, P., Ray,S., Routray, P., Torondel, B., Schmidt, W.P., Bhanja, B. \& Clasen, T. (2014). Promoting latrine construction and use in rural villages practicing open defecation: process evaluation in connection with a randomised controlled trial in Orissa, India. BMC Res Notes.7: 486. doi: 10.1186/1756-0500-7486

Borchgrevink, C.P., Cha, J., \& Kim, S.H. (2013). HandWashing Practices in a College Town Environment. Journal of Environmental Health, 75 (8): 18-24.

Carabin, H., Millogo, A., Cissé, A., Gabriël, S., Sahlu, I., Dorny, P.,.... Ganaba, R. (2015). Prevalence of and Factors Associated with Human Cysticercosis in 60 Villages in Three Provinces of Burkina Faso. PLoS Negl Trop Dis. $\quad 9(11)$ : $\quad$ e0004248. doi: 10.1371/journal.pntd.0004248.

Census Organization of India (2011). Orissa Population Census Data. https://www.censusindia.gov.in/2011Common/CensusData2011.html

Chirwa, C.F.C., Hall, R.P. Krometis, L.H., Vance, E.A., Edwards, A., Guan, T.\& Holm, R.H.(2017). Pit Latrine Fecal Sludge Resistance Using a Dynamic Cone Penetrometer in Low Income Areas in Mzuzu City, Malawi. Int J Environ Res Public Health. $2017 \quad$ Feb; 14(2): 87. doi: $10.3390 /$ ijerph14020087

Curtis, V., Schmidt, W.P., Lubby, S.P., Florez, R. Toure, O., \& Biran, A. (2011). Hygiene: new hopes, new horizons. Lancet Infect Dis, 11 (4): 312-21.

Dalibandhu, P. (2016). Hygienic Practices among the Yanadi Tribe of Nellore District, Andhra Pradesh. South Asian Anthropologist, 16 (1); 65-78.

Dobe, M., Mandal, R.N. \& Jha, A. (2013). Social determinants of good hand-washing practice (GHP) among adolescents in a rural Indian community. Family \& community health. 36(2):172-177.

Duru,C.B., Iwu, A.C., Uwakwe, K.A., Diwe, K.C., Merenu, I.A., Achigbu, K.I., ..... Nwatamole, B.C. (2016). Preventive Practices of Infectious Disease Control and Its SocioDemographic Determinants among Urban Market Attendees in Imo State, Nigeria. International Journal of Health Sciences and Research. ISSN: 2249-9571.

En, W.L. and G. L. Gan (2011). "Factors associated with use of improved water sources and sanitation among rural primary schoolchildren in Pursat Province, Cambodia," Southeast Asian Journal of Tropical Medicine and Public Health, 42(4): 1022-1031.

Ensink, J.H. (2015). WELL FACTSHEET: Health impact of handwashing with soap. (Available from:http://www.lboro.ac.uk/well/resource s/fact-sheets/fact-sheetshtm/Handwashing. htm) [10 May 2015].

Fafunwa, T.S., Mogaji, H.O., Oluwole, A.S., Adeniran, A.A., Fagbenro, M.T., Sam-Wobo, S.O., Bada, B.S. \& Ekpo, U.F. (2017). Water Resource, Hygienic Practice, and Soil Transmitted Helminthiasis in Some Rural Communities of Osun State, Nigeria. Journal of Water Resource and Protection, 9, 99110.https://doi.org/10.4236/jwarp.2017.92 008.

Freeman, M.C., Stocks, M.E., Cumming, O., Jeandron, A., Higgins, J.P., Wolf, J.,... Curtis, V. (2014). Hygiene and health: systematic review of handwashing practices worldwide and update of health effects. Trop Med Int 
Health, $19 \quad$ (8): $\quad 906-$

916.doi:10.1111/tmi.12339.

Jenkins, M.W., Freeman, M.C. \& Freeman, M.C. \&, Routray, P. (2014). Measuring the safety of excreta disposal behavior in India with the new Safe San Index: Reliability, validity and utility. Int J Environ Res Public Health. 11(8):8319-46.

doi:10.3390/ijerph110808319.

Jimenez, A., Cortobius, M., Kjellen, M. (2014). Water, sanitation and hygiene and indigenous peoples: a review of literature. Water International, 39 (3):277-293. https://doi.org/10.1080/02508060.2014.90 3453

Joint Monitoring Program (2015). Progress on Sanitation and drinking water: 2015 update and MDG assessment. Report No. ISBN: 9 789241509145.

Kotloff, K.L., Nataro, J.P., Blackwelder, W.C., Nasrin, D., Farag, T.H., Panchalingam, S., .... Levine, M.M. (2013). Burden and aetiology of diarrhoeal disease in infants and young children in developing countries (the Global Enteric Multicenter Study, GEMS): a prospective, case-control study. Lancet, 382(9888): $\quad$ 209-222.doi:10.1016/S0140$6736 \quad$ (13)60844-2.

Koskei, E.C., Koskei, R.C., Koske, M.C. \& Koech, H.F. (2013). Effect of socioeconomic factors on access to improved water source and basic sanitation in bomet municipality, Kenya. Res. J. Environ. Earth Sc. 5:714-719.

Kunadu, A.P.H., Ofosu, D.B., Aboagye, E., TanoDebrah, K. (2016). Food safety knowledge, attitudes and self-reported practices of food handlers in institutional foodservice in Accra, Ghana. Food Control,69:324330.doi:10.1016/j. foodcont.2016.05.011.

Liberia Institute of Statistics and Geo-Information Services (2009). 2008 National Population and Housing Census. Monrovia, Liberia. www.lisgis.gov.Ir.
Liberia Institute of Statistics and Geo-Information Services (2017). Household Incom and Expenditure Survey 2016. Statistical Abstract. www.lisgis.gov.Ir.

Mukadi, L. N. (2016). Factors Influencing Adoption of Water Sanitation and Hygiene Practices in Kenya: A Case of Shivanga Location, Kakamega County. Dissertation.

Nettey, O.E.A., Enuameh, Y.A., Zandoh, C., Anane, E.A., Abukari, M., Agbokey, F., Dadzie, A.Q., Tivura, M., Adu-Gyasi, D., Febir, L.G., AeNgibise, K.A., Letsa, T., $\quad$ Asante, K.P. \& Owusu-Agyei, S. (2016) Knowledge, Attitudes and Preventive Practices on Ebola Virus Disease in the Kintampo Districts ofGhana.Health,8,1465- 1484. http://dx.doi.org/10.4236/health.2016.8141 46.

Newborne, P. \& Liisanantti, A. (2013). Sanitation and hygiene promotion in rural communities: the Health Extension Programme. Practical Action Publishing. doi:http://dx.doi.org./ 10.3362/9781780447636.006.

Pandey A., Katherine E. Atkins, K.E., Medlock, J., Wenzel, N., Townsend, J.P., .... Galvani, A.P. (2014). Strategies for containing Ebola in West Africa. Science, 346 (6212): 991-995. doi: $10.1126 /$ science.1260612.

Pruss-Ustun, A., Bartram, J., Clasen, T., Colford,J.M., Cumming, O., Curtis, V.,.... Cairncross, S. (2014). Burden of disease from inadequate water, sanitation and hygiene in low-and middle-income settings: a retrospective analysis of data from 145 countries. Trop Med Int Health,19(8):894-905. doi: 10.1111/ tmi.12329.

Rabbi, S.E. \& Dey, N.C. (2013). Exploring the gap between hand washing knowledge and practices in Bangladesh: a cross-sectional comparative study. BMC Public Health, 13: 89. doi: 10.1186/1471-2458-13-89.

Raihan, M.J., Farzana, F.D., Sultana, S., Haque,M.A., Rahman, A.S., Waid, J.L.,.... Ahmed, T. (2017). Examining the relationship between 
socio-economic status, WASH practices and wasting. PLoSONE 12(3): e0172134.doi:10.1371/journal.pone.017213 4.

Roche, R., Bain, R., \& Cumming, O. (2017). A long way to go - Estimates of combined water, sanitation and hygiene coverage for 25 sub-Saharan African countries. PLoS One, 12(2): e0173702. doi: 10.1371/journal.pone.0171783.

Sara, S. \& Graham, J. (2014). Ending Open Defecation in Rural Tanzania: Which Factors Facilitate Latrine Adoption? Int J Environ Res Public Health, 11(9): 9854-9870. doi: 10.3390/ijerph110909854.

Scholz, U., Nagy, G., Gohner, W., Luszczynska, A., \& Kliegel, M. (2009). Changes in selfregulatory cognitions as predictors of smoking and nutrition behavior. Psyhol Health, 24 (5):545-61.

Seimetz, E., Slekiene, J., Friedrich, M.N.D., \& Mosler, H.J. (2017). Identifying behavioral determinants for interventions to increase handwashing practices among primary school children in rural Burundi and urban Zimbabwe. BMC Res Notes. 10:280. DOI10.1186/s13104-017-2599-4.

Sonego, I. L. \& Mosler, H.J. (2014). Why are somelatrines cleaner than others? Determining the factors of habitual cleaning behaviour and latrine cleanliness in rural Burundi. Journal of Water Sanitation and Hygiene Dev. (2) 257267. doi: 10.2166/washdev.2014.147.

Thys, S., Mwape, K.E., Lefèvre, P., Dorny, P., Marcotty, T., Phiri, A.M., Phiri, I.K., Gabriël, S.(2015). Why Latrines Are Not Used: Communities' Perceptions and Practices Regarding Latrines in a Taenia solium Endemic Rural Area in Eastern Zambia. PLoS Negl Trop Dis. 9(3): e0003570. doi: $10.1371 /$ journal.pntd.0003570.

Thys, S., Mwape, K.E., Lefèvre, P., Dorny, P., Phiri, A.M., Marcotty, T., Phiri, I.K., \& Gabriël,
S.(2016). Why pigs are free-roaming: Communities' perceptions, knowledge and practices regarding pig management and taeniosis/cysticercosis in a Taenia solium endemic rural area in Eastern Zambia. Vet Parasitol., 225:33-42. doi: 10.1016/j.vetpar.2016.05.029.

UNICEF (2008). Final Report of the Malawi Multiple Indicator Cluster Survey, 2006. UNICEF Statistics Office. Lilongwe, Malawi

UNICEF/WHO (2012). Progress on Drinking Water and Sanitation: 2012 Update. New York: UNICEF/WHOVenkatashiva, R.B., Kusuma, Y.S., Pandav, C.S., Goswami, A.K., Krishnan, A. (2017).Water, Sanitation and Hygiene Practices for Under-Five Children among Households of Sugali Tribe of Chittoor District, Andhra Pradesh, India. Journal of Environmental and Public Health, 2017: 1-7. https://dor.org/10.1155/2017/7517414.

WASH Liberia Baseline Study (2013). A 2013study on current community access to, and practices on water, sanitation and hygiene in select rural and urban settlements in Liberia.

Winch, P., Martin, N., \& Hulland, K. (2014). What factors affect sustained adoption of water, sanitation and hygiene technologies: a systematic review. John Hopkins Bloomberg School of Public Health.

WHO \& UNICEF. (2013a). Progress on Sanitation and Drinking Water. 2013 Update. Geneva. World Health Organization.

WHO \& UNICEF (2013b). WHO/UNICEF Joint Monitoring Programme (JMP)for watersupply and sanitation.http: //www.wssinfo.org/data- estimates/ introduction/

World Health Organization (2013). Fact sheets: Diarrhoeal disease, 2013. Available at: http://www.who.int/mediacentre/factsheet s/fs330/en/. Accessed 27 Mar. 2016. 